\title{
Faculty's Social Media usage in Higher Education Embrace Change or Left Behind
}

\author{
Seren Başaran \\ Computer Information Systems, Near East University, Lefkoşa 98010, via: Mersin 10 Turkey, Cyprus \\ European Centre for Research and Academic Affairs (ECRAA), PO Box 1045, Lefkoşa, via: Mersin 10, Turkey, Cyprus
}

\begin{abstract}
This paper addresses faculty members' (academic staff) viewpoints on benefits, barriers and concerns of utilizing social media and also investigates differences with respect to their social media experience in teaching, age and the purpose of using social media. The data was collected through an adopted questionnaire from 324 faculty members of two public and two private universities in north part of Cyprus and was analyzed through descriptive statistics, independent samples t-test and one-way ANOVA. Results revealed that, although faculty members appreciate benefits of using social media, they do have concerns and they are aware of barriers almost as to same degree as benefits of using social media. Those who are familiar and have used social media before think more about concerns than those who haven't used it. Elder faculty members possess less concern about using social media than their younger and middle age colleagues. Furthermore, the purpose (personal, educational, professional) of using social media has no effect on faculty members' viewpoints on benefits, concerns and barriers of using social media. Abundant literature on social media usage from students' perspective and relatively limited studies examining teachers/instructors point of views on social media use particularly for developing countries constitute the primary motivation behind the emergence of such research. Faculty members should be endorsed to adopt social media for instructional and professional purpose and misconceptions about using social media and barriers should be eliminated to enhance conscious utilization of social media for teaching.
\end{abstract}

Keywords-Academic staff; age; purpose; social media experience; social networking sites; university

\section{INTRODUCTION}

Social media platform offers sharing of information through enabling digital communication and interaction among all stake holders. It offers not only use of emerging technologies but also maintains open, flexible, anytime accessible environment for all individuals from diverse backgrounds [1]. The most popular social media tools with remarkably growing usage rates in recent years which caught salient attention are; Facebook, YouTube, Wikipedia, Twitter, LinkedIn, Pinterest and Instagram.

Utilization of such social media tools has been the central focus of recent studies which emphasize current advancements in educational aspects of digitally interactive and mobile technologies within the last decade. Social media tools are used predominantly by students subsequently by teachers and by faculty members (academic staff) and to some extent by higher educational institutions' administrations who try to keep up with such new emerging trend with attempts to incorporate social media into their educational milieu.

Today it is not uncommon for a higher education professional to own an account in any of those social media platforms for disseminating information in the combination of either text, link, photo or video, and engage actively for personal, instructional or profession related purposes. With the emergence of such new technologies, social media usage has been growing fast and rapidly penetrates educational settings. This pervasive characteristic of social media has made it possible either formally or most of the time informally to integrate itself into educational environments and it has already gained acceptance from students while it has been recently considered by faculty and educational institutions [2]. With this recent and ongoing development, higher education professionals particularly faculty members could not ignore anymore the influence of social media on students [3], [4].

Despite ubiquitous utilization of social media, little is known about faculty members' readiness and willingness to adopt social media in their instruction as an emerging tool. As mentioned in majority of the studies, benefits of utilizing social media could not be underestimated however, higher education professionals who are thought to be regarded as more refined users as compared to students, are still acting cautiously about embracing and integrating social media into daily life and into educational practice due to numerous existing concerns, barriers and challenges [2], [5], [6], [7], [8], [9]. While some higher education professionals take social media as an opportunity to communicate digitally with their highly connected, technologically savvy students who require immediate online response, others still consider it as complicated tool for implementation [10], [11].

At this point, understanding barriers, concerns of using social media along with benefits from faculty members' viewpoints are crucial for identifying and determining best practices to encourage faculty-student interaction and promoting effectiveness of teaching and learning. In addition, once challenges are identified, taking necessary precautions shall follow easily. Moreover, identifying benefits is essential for grasping current trends and the state of social media usage in higher education institutions which will definitely provide valuable clues to foresee emerging future directions in that respect. 


\section{RELATED RESEARCH}

Extensive body of literature focused on various aspects of social media usage. Despite the diverse literature on the utilization of social media focusing on student perspectives, relatively limited studies have been located which primarily concentrated on how faculty perceive, adopt and utilize social media [2], [9], [12]-[24]. This paper intends to focus on faculty viewpoint rather than students' views in order to fill this important gap in the literature.

Studies involving higher education professionals have identified three different purposes of using social media as; personal, professional and educational/instructional/ pedagogical. The personal use is defined as using social media as a tool for communication, interaction for individual needs and for self-enjoyment. Professional use of social media is defined as using social media for academic engagement, improvement and collaboration. Instructional use is defined as implementing social media into teaching and learning practices. Principally, personal use of social media has been constantly reported to outscore professional and/or educational use among faculty members [9]. Relevant literature additionally addressed the utilization of social media either through descriptive information about usage, benefits, major concerns and/or barriers. For instance, researchers in [17] conducted a qualitative study where three faculty members were interviewed in order to understand their experiences with social media usage. Some of the findings are about concerns of establishing clear cut boundaries between professional and personal use, and lack of efficient time usage. Different uses of social media has not been fully identified and yet sought to be investigated further.

The extant literature shows notable variations between the personal, professional and instructional use of social media with respect to different regions. For instance, authors in [25] conducted a study to understand the functions of social media usage and opinions of 31 faculty members' towards instructional use of social media. The study revealed positive opinions on delivering content to meet the requirements of their technologically eligible students through interaction. Yet there is paucity of research on how professionals prefer to use social media particularly in a developing country namely north part of Cyprus or whether they are using it for both aforementioned three purposes evenly or whether they heavily rely on personal use only. Nevertheless instructional use of social media is overlooked by the literature in general. It is important to identify and differentiate between three different purposes of utilizing social media and the effect of these on the faculty viewpoints. The results of this paper may shed light upon on how to maintain balanced use of social media.

In addition, vast majority of the studies predominantly rely upon the data obtained through self-report surveys as data collection tool. Such studies are known to be quite beneficial to acquire initial insights about current status and future trends. This research in a similar fashion intends to use self-report study design for convenience.

The two existing wide scale self-report surveys conducted by the Babson survey Research Group and Pearson have revealed that while more and more faculty members are using social media for professional purpose, each year instructional use has fallen behind the professional use. This result might have different explanations; either faculty members as users can be regarded 'picky' in selecting particular type of social media tools for their instruction or they are not adequately equipped with potential skills to choose and employ proper social media tools for their teaching and learning practices or they do not wish to adjust their usual conventional, educational strategies which they are quite comfortable with. Furthermore, faculty are aware of and engage actively with popular social media tools however, still major concerns about privacy and integrity continue to exist.

Similar self-report data studies additionally referred various demographic attributes based differences on the utilization of social media. The authors in [26] conducted a self-report study to examine advantages and barriers of social media usage among faculty members $(n=116)$ with respect to gender, academic position and interaction based differences which no significant discrepancies have been reported. There is still dearth of research on demographic attributes based on the differences of social media usage by faculty. Addressing the impacts of age, social media usage experience and purpose on the challenges and opportunities of using social media are barely the major concerns of current studies [27].

The important attributes such as age and utilization namely voluntariness of use are correspondingly among influential components of widely recognized model of the Unified Theory of Acceptance and Use of Technology (UTAUT). This well recognized model is used to interpret individuals' likelihood of adopting and utilizing specific technology, in this case; social media. Gender, age, experience, voluntariness of use, income and education are well known demographic attributes of this model. Starting off from this inspirational point, this study aims to inspect any variations with respect to age, experience of using social media and purpose of using it.

Poor and well implementations of social media into instruction could lead to immense difference. While social media is thought to facilitate communication, active engagement, group work and it enhances the teaching activities when utilized in class sessions, it could be recognized as an essential element in providing such features for faculty members as well. However, if not utilized well, it could also lead to distraction.

Studies indicated that although leading perception about the use of social media technologies for education is positive, faculty still faces with problems to overcome stated barriers in adopting social media. Faculty members encounter many demands in implementing social media tools with varied support, and eventually they approach to the implementation of such tools up to some degree of hesitation as to whether these tools are worth the effort.

Furthermore, studies occasionally indicated opposing results on student/faculty concerns about educational adaptation of social media. Most of the time studies reported benefits of the use of social media as their primary purpose and have stated exceedingly optimistic results about social media [2], [18]. Thus, on the contrary to the existing literature, the 
aim of this paper is to elaborate primarily on concerns and barriers along with benefits of using social media.

A systematic review of the literature of 11 studies in the field of business education conducted by [2] revealed that faculty greeted adaption of Web 2.0 applications namely social media less warmly and moreover they reflected upon the diverse amount of social media tools and the lack of supportive knowledge and IT maintenance in using such tools. In a study conducted by [28] which was also reviewed by [2], it was remarked that faculty and administration resist against the instructional adaptation of social media which might be as a result of elder faculty members hesitate to leave their 'comfort zone' of ongoing conventional approaches. It was pointed out that young academic staff already integrated social media in their personal, educational and professional practices while older faculty could not fully embrace the use of social media yet [29]. Moreover, in self-report study conducted by [24], faculty responded negative views about instructional use of social media due to the wide diversity of available tools and faculty's lack of knowledge on how to use them. The results indicated that social media are seen as complicated tool to be used particularly by older faculty members. Another study reporting about the concerns is [30] which conducted a qualitative study based on semi-structured interviews with 51 academicians on the professional use social media. They found out that academicians most widely use Wikis, Facebook and Blogs along with other tools. They remarked that they use social media for making connections with peers, to collaborate and to publicize their research. They pointed out that protection of privacy is a main concern. They have expressed ambivalent statements about adopting it due to the lack of social media tools particularly for professional use. In addition, authors in [31] summarized that risk of security and privacy issues, loss of control, teachers' unwillingness to adapt social media in their teaching are considered among the main barriers to social media usage in higher education.

To sum up, there exist numerous gaps in the current state of field and this study aims to fill these gaps. Firstly, faculty perspective is less focused in literature as compared to student views; secondly, in contrast to prevalent overstated optimistic findings about social media usage, the primary purpose of this paper is to address predominantly barriers and concerns together with benefits; thirdly, relatively few studies located addressing on demographic/affective differences on the utilization of social media which are regarded as influential components UTAUT model; and lastly to portray social media usage trends of higher education professionals particularly in north part of Cyprus which constitutes a noteworthy case on potential usage of social media in higher education institutions in developing countries. The paper should be of interest to readers in the areas of higher education, social media and technology acceptance research particularly for developing countries. Identified concerns and barriers as the outcomes of this study could be considered by policy makers, higher education administrations in order to resolve current conflicts and challenges of social media usage.

\section{METHODOLOGY}

\section{A. Research Questions}

The corresponding research questions are:

1) What are the current state of faculty members' viewpoints on benefits, barriers and concerns on social media usage?

2) Do faculty members' viewpoints on benefits, concerns and barriers of using social media differ with respect to experience with social media use in their teaching?

3) Do faculty members' viewpoints regarding benefits, concerns and barriers of social media usage differ with respect to age?

4) Do faculty members' viewpoints on benefits, concerns and barriers of using social media differ with respect to the purpose (personal, professional and educational) of using social media?

a) Is there a significant difference with respect to rate of utilizing social media for personal purpose on faculty's viewpoints about benefits, concerns and barriers of social media usage?

$b$ ) Is there a significant difference with respect to rate of utilizing social media for educational purpose on faculty's viewpoints about benefits, concerns and barriers of social media usage?

c) Is there a significant difference with respect to rate of utilizing social media for professional purpose on faculty's viewpoints about benefits, concerns and barriers of social media usage?

\section{B. Participants}

The data was collected from both public and private universities through purposive sampling technique. The sample was rigorously selected in a manner to represent general population. Initially, two public and two private universities were selected then among four universities, common departments were chosen in a way that half of the faculty members are believed to be more familiar with social media and use it more often and the other half are thought to utilize social media less and hence likely to possess less experience with social media. The reason for such selection process is to free results from biased judgments and to maintain balance in responses.

400 faculty members in total accepted the questionnaire and only 324 valid questionnaires were collected from participants. Demographic information about participants were given in Table I. Participants are $53.3 \%$ female $(n=173)$ and $46.6 \%$ male $(n=151) .45 .4 \%(n=146)$ of the faculty are of age less than $30,47.2 \%(n=153)$ of the faculty are between $30-50$ years of age. Only $7.7 \%$ (25) of the faculty is older than 50 years of age. $41.7 \% \quad(n=135)$ of the faculty has teaching experience less than 5 years and between $5-10$ years $(n=135)$. Only $16.7 \% \quad(n=54)$ of the faculty have teaching experience more than 10 years. Regarding the social media usage, $43.5 \%$ $(n=141)$ of the faculty have used social media in their teaching and $56.5 \%(n=183)$ of the faculty haven't used social media in their teaching before. 
TABLE. I. DEMOGRAPHIC INFORMATION OF PARTICIPANTS

\begin{tabular}{|l|l|l|l|}
\hline \multirow{3}{*}{ Gender } & & Frequency & Percentage (\%) \\
\hline \multirow{3}{*}{ Age } & Female & 173 & 53.4 \\
\cline { 2 - 4 } & Male & 151 & 46.6 \\
\hline \multirow{3}{*}{ Teaching Experience } & $<30$ & 146 & 45.4 \\
\cline { 2 - 4 } & $30-50$ & 153 & 47.2 \\
\cline { 2 - 4 } & $>50$ & 25 & 7.7 \\
\cline { 2 - 4 } & $<5$ years & 135 & 41.7 \\
\cline { 2 - 4 } $\begin{array}{l}\text { Social media experience } \\
\text { in teaching }\end{array}$ & $>10$ years & 135 & 41.7 \\
\cline { 2 - 4 } & Yes & 54 & 16.7 \\
\cline { 2 - 4 } & No & 141 & 43.5 \\
\hline
\end{tabular}

Using Social Media for personal, professional and educational purposes were given in Fig. 1. 8\% $(\mathrm{n}=26)$ rarely, $36.7 \%$ sometimes use $(\mathrm{n}=119)$ while $55.2 \%(\mathrm{n}=179)$ often use social media for personal purposes. $11.7 \%(\mathrm{n}=38)$ rarely, $50.6 \%(\mathrm{n}=164)$ sometimes while $38.0 \%(\mathrm{n}=122)$ often use social media for educational purposes. $43.2 \%(\mathrm{n}=140)$ rarely, 40.0\% ( $\mathrm{n}=130)$ sometimes and $16.7 \%(\mathrm{n}=54)$ often utilize social media for professional purposes.

\section{Data Collection}

As for conceptual basis, social media usage in higher education is still approached by many faculty members with some degree of hesitation and hence they are not willing to integrate social media in their educational practices. On the other hand, it has been noted in considerable amount of studies that faculty has greater incentive to employ such tools for personal purposes, given increasing dependence on such tools in the profession, final research questions of this study will shed light on the current status of social media usage by faculty members.

It is very important to understand the viewpoints that faculty members develop which might differ from other faculty members with respect to aforementioned attributes. In order to strengthen the conceptual basis for understanding the effect of benefits, barriers, concerns have on the successful adoption of social media at universities this study provides a basis for a framework for identifying and prioritizing issues and barriers affecting successful adoption of social media in instruction. In addition, identification of these barriers enables a greater understanding and developing effective strategies to implement social media into classroom environment. Relative benefits, barriers and concerns have been mainly drawn from UTAUT studies, diffusion of innovation (DOI) and TAM (Technology acceptance model).

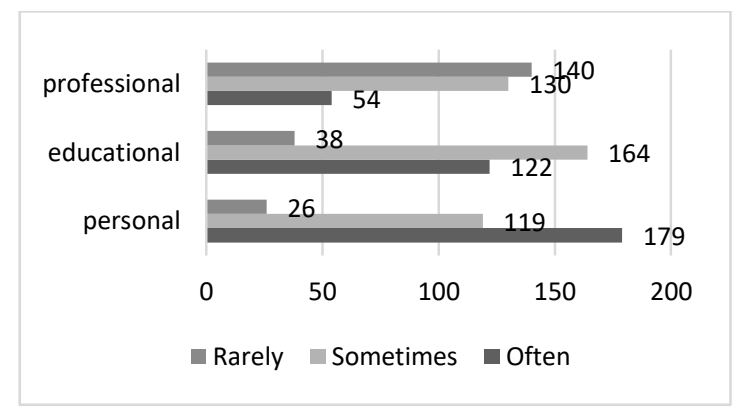

Fig. 1. Purpose of using Social Media.
To investigate these issues, a questionnaire was adapted from similar studies to measure relevant variables. Specifically, the questionnaire was designed to ask participants about potential anticipated factors that take part in the emergence of faculty members' utilization of social media.

Questions from a similar survey conducted in the United States by Babson research Group were adapted to capture the status and differences universities in north part of Cyprus. After necessary changes were made to determine the perceived benefits, current concerns and barriers faced by faculty members. To determine the current status of social media usage, respondents were asked if they have already used social media in their teaching and the rate and purpose of using social media.

The first part of the questionnaire includes personal information such as gender, age, teaching experience, social media usage experience and purpose of using social media. This questionnaire is designed to develop a strategy to that requires an understanding of both benefits to be gained and barriers to be overcome. The demographic items regarding age, gender, teaching experience and purpose of using social media, usage trends of faculty members and concerns related items and barriers were revised from Pearson social media survey [9]. The benefits dimension (items 1-10) and some items regarding concerns dimension (11-18) Likert type items were adapted from [26]. The last section is divided into three dimensions as; benefits of using social media (BNF, 10 items), concerns (CRN, 13 items) and barriers (BRR, 9 items). The items were rated by 5 option Likert scale ranging from "Strongly Disagree" to "Strongly Agree".

\section{Procedure and Research Design}

The questionnaire was conducted in English to faculty members of the predetermined departments. The questionnaire were distributed to 400 faculty members in four universities in north part of Cyprus and the responses were retrieved from all faculty members in every five day intervals. From these public and private universities faculties and departments which are common were chosen to represent sample adequately. The data was collected within 3 months from a valid sample of 324 faculty members at the academic year 2016 .

This study is a cross-sectional and quantitative investigating discrepancies among already existing groups in order to identify consequences of these differences which can be classified as causal comparative design. The independent variables are 'age', 'social media experience' and 'purpose of utilizing social media'. The dependent variables are calculated average scores of the item responses for sub-dimensions of the questionnaire which are BNF (benefits), CRN (concerns) and BRR (barriers).

\section{E. Data Analysis}

In order to answer research question 1, descriptive statistics such as means and standard deviations were employed; Independent samples t-test was applied for investigation of the research question 2 and for research questions 3 and 4, oneway ANOVA between subjects were executed to analyze data in SPSS. SPSSv26 was used for conducting exploratory factor analysis and LISRELv8.80 was used to perform confirmatory factor analysis. 


\section{F. Validity and Reliability}

Since benefits, barriers and concerns dimensions were adapted from different studies initially exploratory and subsequently confirmatory factor analyses were executed to 32 Likert type items for predetermined dimensions of the questionnaire as benefits, concerns and barriers in order to obtain evidence for construct related validity.

The measure of the sampling adequacy was obtained as 0.881 is between 0.80 and 0.89 which was rated as meritorious [32] and Bartlett's test of sphericity was significant $(\chi 2(496)=$ $3096.596, \mathrm{p}<.05)$. The communalities were all higher than 0.4 showing the items contribute to other items' variances. Principle components analysis with Varimax rotation of the three factor solution, explained $42.02 \%$ of the variance, was used due to its theoretical foundation which was also supported by the Scree plot result where eigenvalues level off three factors. The descriptive statistics, eigenvalues, percentage, and cumulative percentages and Cronbach's alpha reliability values of theses 3 factors were presented in Table II. The factor loading matrix for this final solution is presented in Table II. The results of the factor analysis matched with the predetermined dimensions supporting the evidence for construct related validity. Table III shows both factor loadings of each item and also it's mean and standard deviation for convenience. The Cronbach's alpha reliability of the subdimensions of the questionnaire are as follows; BNF (1-10 items) 0.82, CRN (11-23 items) 0.79, BRR (24-32 items) 0.84. Cronbach's alpha reliability for the questionnaire in total was computed as .89 having good internal consistency [33]. Thus, the adapted questionnaire is considered as valid and reliable instrument and further statistical analyses on the data could then be executed.

Confirmatory factor analysis was later performed in order to justify the results of exploratory factor analysis which the model comprised of 3 latent variables (benefits, barriers and concerns) in the original scale and 32 observed variables (items of scale; item1(Q1), item2(Q2), item32(Q32) which is given in Fig. 2. Reported goodness of fit indices are; Chi-square $\left(\chi^{2}\right)$, chi-square/df ratio (acceptable if less than 2.0), non-normed fit index (NNFI, acceptable if .90 or greater), normed fit index (NFI, best if .90 or greater, acceptable if greater than .80), rootmean-square error of approximation (RMSEA acceptable if .05 or less), goodness of fit index (GFI), adjusted GFI(AGFI), comparative fit index(CFI), incremental fit index(IFI) is best if .90 or greater, acceptable if greater than .80$)$, and standardized root mean square residual(S-RMR) is best if less than or equal to .08 [34] The maximum likelihood estimation of the three factor model indicated that the model was good fit of the data with the indices calculated as:

$\chi 2(311, \mathrm{~N}=324)=476.15 ; \chi 2 / \mathrm{df}=1.53 ; \mathrm{NNFI}=.91 ; \mathrm{NFI}=$ $.82 ; \mathrm{RMSEA}=.04, \mathrm{~S}-\mathrm{RMR}=0.0562, \mathrm{GFI}=0.90, \mathrm{AGFI}=0.88$, $\mathrm{CFI}=0.92, \mathrm{IFI}=0.93$. In addition, all factor loadings were statistically significant at the $\mathrm{p}<.01$ level suggesting that the three factors were well constructed by the items. It could be concluded that there exists an adequate fit of the aforementioned attributes to the data.

\section{RESULTS}

\section{A. The Current State of Faculty Members' Viewpoints}

Sought for an answer for the research question 1, Table III depicts faculty members' responses to 32 Likert type items regarding benefits, concerns and barriers of using social media in teaching. According to the mean scores shown at the Table III, the constructs with the largest mean ("Strongly disagree" is coded as 1 and "Strongly agree" is coded as 5) are those that the faculty respondents have deemed to be the most agreeing. The mean scores for faculty members' viewpoints on barriers $(\mathrm{M}=3.69, \mathrm{SD}=0.65)$, benefits $(\mathrm{M}=3.74, \mathrm{SD}=0.62)$ and concerns $(\mathrm{M}=3.72, \mathrm{SD}=0.50)$.

The findings showed that faculty almost agrees with benefits of using social media while they also agree almost as the same degree on specified concerns about using social media in their teaching. On the other hand, faculty members could not ignore barriers regarding the social media usage. Altogether, they possess positive opinions about social media usage in teaching while keeping in mind barriers and not ignoring the concerns when using social media in their classrooms.

\section{B. Impact of Social Media Experience on Faculty Viewpoints}

To answer research question 2 , independent samples t-test was performed to compare benefits, concerns and barriers of using social media with respect to former experience of social media use. There are significant differences in the average scores of concerns on using social media not before $(M=3.77$, $\mathrm{SD}=0.51)$ and having used social media in teaching before $(\mathrm{M}=3.65, \mathrm{SD}=0.49) ; \mathrm{t}(322)=-2.04, \mathrm{p}=0.04)$. Faculty members who have used social media in their classes before possess less concerns about using social media as compared to faculty members who haven't used social media before.

In addition there exist significant differences detected in the average scores of barriers on using social media not before $(\mathrm{M}=3.79, \mathrm{SD}=0.67)$ and having used social media before $(\mathrm{M}=3.56, \mathrm{SD}=0.62) ; \mathrm{t}(322)=-3.18, \mathrm{p}=0.00)$. Faculty members who have used social media before are less concerned about barriers of using social media in their instruction as compared to faculty members who haven't used social media before. There exists no significant difference with respect to benefits of using social media $(\mathrm{t}(322)=-0.70, \mathrm{p}=0.48)$.

To sum up while earlier experience with social media in teaching has effect on concerns and barriers it does not have any effect on benefits of using social media. Specifically, findings suggest that faculty members who have used social media in teaching before are significantly less worried about concerns and barriers of using social media.

\section{Impact of Age on Faculty Members' Viewpoints}

To answer research question 3, one-way ANOVA between subjects was performed to compare the effect of age less than 30 years, between $30-50$ years and more than 50 years on benefits, barriers and concerns of using social media. There was a significant effect of age on faculty's concerns of utilizing social media at the $\mathrm{p}<0.05$ level $[\mathrm{F}(2,321)=5.26, \mathrm{p}=0.01$. $]$ 
Post hoc comparisons using the LSD test was used for the correction of unequal group sizes yielded that mean scores of age range less than $30(\mathrm{M}=3.73, \mathrm{SD}=0.50)$ and more than 50 $(\mathrm{M}=3.41, \mathrm{SD}=0.59)$ a significant difference exists. Faculty members of less than 30 years of age have more concerns as compared to faculty members more than 50 years of age in utilizing social media.

In addition, Post hoc comparisons using the LSD test for correction of unequal group sizes yielded that mean scores of age range between 30 and $50(\mathrm{M}=3.76, \mathrm{SD}=0.47)$ and more than $50(\mathrm{M}=3.41, \mathrm{SD}=0.59)$ a significant difference exists. Faculty members between 30-50 ages old have more concerns as compared to faculty members more than 50 years of age in utilizing social media.

To sum up, older faculty members have less concern about using social media than their young and middle age colleagues.

\section{Impact of Purpose on Faculty Members' Viewpoints}

To answer research question 4a, one-way ANOVA between subjects was performed to compare the effect of using social media for personal purposes on benefits, barriers and concerns of using social media. There was no significant effect of using social media for personal purposes on the three dimensions $[\mathrm{F}(2,321)=1.38, \mathrm{p}=0.25]$ for $\mathrm{BNF},[\mathrm{F}(2,321)=$ $0.77, p=0.46]$ for $C R N,[F(2,321)=0.67, p=0.51]$ for $B R R$ at the significance level of 0.05 . To sum up, personal use of social media has no effect on faculty members' viewpoints on benefits, concerns and barriers of using social media.

To answer research question $4 \mathrm{~b}$, one-way ANOVA between subjects was performed to compare the effect of using social media for professional purposes on benefits, barriers and concerns of using social media. There was a no significant effect of using social media for professional purposes on the three dimensions $[\mathrm{F}(2,321)=0.26, \mathrm{p}=0.77]$ for $\mathrm{BNF},[\mathrm{F}(2$, $321)=0.32, \mathrm{p}=0.72]$ for $\mathrm{CRN},[\mathrm{F}(2,321)=0.61, \mathrm{p}=0.54]$ for BRR at the 0.05 level of significance. To sum up, professional use of social media has no effect on faculty members' viewpoints on benefits, concerns and barriers of using social media.

To answer research question 4c, one-way ANOVA between subjects was performed to compare the effect of using social media for educational purposes on benefits, barriers and concerns of using social media. There was a no significant effect of using social media for educational purposes on the three dimensions $[\mathrm{F}(2,321)=1.99, \mathrm{p}=0.14]$ for $\mathrm{BNF},[\mathrm{F}(2$, $321)=0.04, p=0.95]$ for $\mathrm{CRN},[\mathrm{F}(2,321)=0.31, \mathrm{p}=0.73]$ for BRR. To sum up, educational use of social media has no effect on faculty members' viewpoints on benefits, concerns and barriers of using social media.

In overall, the type of purpose of using social media has no effect on faculty members' viewpoints regarding benefits, concerns and barriers of utilizing social media.

\section{DISCUSSION}

This study sought to understand barriers, benefits and concerns of utilizing social media among faculty members in personal, professional and instructional practices concurrently with numerous differences with respect to age, experience and purpose of usage.

Faculty possesses positive opinions about social media usage in teaching while keeping in mind barriers and not ignoring the concerns when using social media in their classrooms. Personal use is most preferred type of usage and then comes educational use and lastly professional use. Faculty members having used social media before significantly possess less concern and think less about barriers of using social media in their instruction. Therefore faculty members who haven't utilized social media are more likely to be less positive about using social media in their practices. Older faculty members have less concern about using social media than their young and middle age colleagues. The purpose (personal, educational, professional) of using social media has no effect on faculty members' viewpoints regarding benefits, concerns and barriers of utilizing social media.

At first glance, findings indicated that major concerns are related to privacy, losing authority over students in a digital environment and copyright issues. Similar threats were mentioned other researchers in the literature [30], [31], [35]. The faculty agrees to use social media if they see that students and colleagues use social media dominantly. This could be explained by 'social influence' factor as in the model of UTAUT (Unified Theory of Acceptance and Use of Technology) which is believed to influential factor in the adoption of any technology in this case, social media usage [30].

Another noteworthy aspect is faculty's awareness of most popular social media tools. Further measures of faculty utilization of social media for personal and professional purposes can then be adjusted by the familiarity of faculty members for popular social media platforms. As an expected outcome, the majority of faculty members are familiar and are aware of popular social media tools and use them. This finding is in line with previous studies [9], [36]. In this study, faculty often uses social media for personal purposes while they sometimes use it for instructional purposes and rarely use it for professional purposes.

While personal use of social media is culminated in other sources as well, the precedence is that professional use followed lastly by instructional use [9], [36]. The reason for this contradictory finding might be due to students are already comfortable in using social media which established crucial motive for faculty to adapt social media for instructional purpose. Some studies indicated that boundaries between professional and personal use of social media are not clearly set or lost [15], [30]. Hence in this case, professional use might have been subsumed by the personal use.

Although faculty members agree and appreciate benefits of using social media in instruction they have concerns and are aware of the barriers almost as same degree as being aware of benefits of using social media. This is in agreement with [37] who conducted a study with 195 faculty members where almost half of faculty respondents have used social media for instructional purposes and reflected more on the concerns of using social media which they believe social media yields to distraction. It was remarked by the author in [2] that the nearly 
half of the studies that he reviewed $(n=12)$ faculty stated contrary findings, negative results, expressed concerns, and restrictions about using social media. Additionally, studies might have overstated positive aspects of using social media for educational purpose and might tend to overlook potential disadvantages causing misleading ideas about implementation of social media [2]. In this respect, this study is believed to equally mentioned pros and cons of social media utilization. Besides, consistent findings were mentioned by authors in [18] who also addressed that faculty is positive about using social media within educational milieu. At the same time, they seem to be careful about adopting it and they also conveyed their concerns about it. Similar alertness to partial approval of social media usage also exists in other studies. For instance, [13] examined faculty's adoption of Web 2.0 technologies with 136 university instructors; faculty appreciate the value of social media usage in instruction, but for some reason they do not plan to use it for instructional purpose. In another study by [24] barriers of using social media for instructional purpose were investigated. Although they were positive about instructional use, they are cautious about certain perils to social media adoption such as lack of time and the vast amount of available tools. In [30], participants stated privacy as the major concern behind the hesitation of faculty's thoroughly adopting social media tools. Apparently, faculty seems to value non-negligible potential of social media and it's adaptation to instructional practice. However, as it was also pointed out with this research, concerns about privacy, copyright issues and difficulty of monitoring student experiences still remain as the main concerns in the literature. In literature, wholeheartedly adoption of social media by the faculty will remain limited till then [2], [18], [21].

The aforementioned concerns that were persistently mentioned in studies could be classified into four main categories as; individual, student, institution and management related issues. The researchers remarked upon all these concerns might be due to a fallacy of perceiving that social media could only be used for social/personal purposes and is not suitable for instructional purpose [21].

Faculty members having used social media before significantly possess less concern and think less about barriers of using social media in their instruction. Therefore faculty members who haven't utilized social media are very likely to hold less positive views about using social media.

Older faculty members have less concern about using social media than their young and middle age colleagues. Reason behind this outcome would be while young faculty are more actively engaged in social media, the burden of using social media could be more tangible to them as compared to the elder faculty who engage less with social media. In contrast, [38] indicated an opposing result in a qualitative study conducted with 10 university advisers with ages ranging from 25 to 74, no eloquent relation detected between age and social media usage where older academic advisers appreciate the positive impact of social media usage in higher education environments as same degree as their younger counterparts. Authors in [12] noted non-significant effect of age on social media usage in teaching among 65 faculty members with faculty agreeing almost same to the benefits and barriers of social media use.
Faculty members quite often use social media for personal purposes and they sometimes use it for instructional/educational purposes and lastly they indicated that they rarely use it for professional purposes. It was reported that social media tools used for professional purpose were listed from highest to lowest popularity are Wikis, Facebook and Blogs [30].

The purpose (personal, educational, professional) of using social media has no effect on faculty members' perspectives on benefits, concerns and barriers of utilizing social media. There exists paucity of research in detecting certain discrepancies on opportunities and challenges of utilizing social media. One of the rarely located studies is that, authors in [26] who conducted a survey with 15 Likert type questions, some demographic information and open ended questions to faculty members $(n=112)$ to identify concerns and barriers of using social media and to note differences with respect to gender and academic position. They reported no difference in the concerns and barriers with respect to gender. In addition, there was no interaction between academic position and gender to the concerns and barriers related perspectives of the faculty. Factors like age, experience and utilization which are among influential components of well-known model of the UTAUT model for adopting and utilizing specific technology, in this case social media which should be focused more in future.

It was remarked that academic staff should invent new ways to keep in touch with their students to dissolve existing detachments between teaching, learning and real life [39]. In addition, increase interest on social media by students encourages academic staff more to embed social media in their classroom practices [40]. Exponential growth in educational use of social media is expected to continue [41]. However addressed issues should be resolved regarding concerns about the privacy and integrity which cause premature adoption and will continue to interrupt faculty's use of social media particularly in instructional and professional practices. Similar concerns were noted by faculty regarding confidentiality of data in using cloud environment for educational practices [42]. Embedding social media into flipped learning and exploring learning, engagement, motivation and interaction of learners, particularly faculty will provide valuable insights in that respect [43].

\section{LIMITATIONS}

As a limitation, self-report data obtained through surveys yield to depend on the honesty and insight of the participants which likely to result with misleading inferences to some extent. Faculty members of from local universities completed the questionnaire. Thus, the external validity and generalizability could be limited.

\section{CONCLUSION}

With the immense diversity and pervasiveness of social media tools, faculty members who are already aware and use social media in their daily practices started to embrace social media more and more for educational practices as well. In contrast to prevalent impression which young faculty are thought to be more capable of using social media, older faculty seems to value and use social media as much as their young 
colleagues. In addition, faculty feels agreeable to use it if they see that students and colleagues use social media dominantly. This is due to the pervasive impact and social influence as mentioned in UTAUT theory.

Most of the faculty members are aware of popular social media tools and use them. While they often use social media for personal purposes, they sometimes use it for educational purposes and rarely use it for professional purposes. Professional use with the introduction of emerging, innovative solutions will be expected to inflate within a decade. Although faculty members agree and appreciate benefits of using social media in instruction they still have concerns and are aware of the barriers almost as same degree as being aware of benefits of using social media.

Majority of faculty members lack knowledge to leverage social media properly. It is imperative that faculty members must themselves be very competent in social media usage to explore opportunities to implement a social media in their instruction, and should keep up regularly following recent trends and adapt it to demands of todays' students.

Research findings provide up-to-date picture of social media usage among faculty members and intend to aid policy makers, higher education institution administrations and faculty to develop a future plan for the adaptation of social media more for professional and instructional practices through minimizing barriers and concerns mentioned in this study.

\section{FUTURE RECOMMENDATIONS}

The ubiquity of social media in the classroom is inevitable and could lead to certain challenges. While use of social media is extremely high among faculty, the impact of these in implementation to the educational setting is relatively low compared to more traditional forms. Implementations on how to leverage social media requires further investigation.

Faculty members mostly indicated concerns are about privacy issues, losing authority over students in a digital environment and copyright issues. Unless novel solutions are not proposed in near future, these issues may resist to exist and prevent faculty members from wholeheartedly accepting social media.

A longitudinal data could be beneficial in more depth understanding of faculty's use of social media which may yield to identifying general outline, critical contributors and the transition over time. More empirical based research is required to understand adoption of social media in higher education in future.

Faculty should be endorsed by training programs provided by academic institutions on how to implement social media in their educational practice and how they can benefit from social media for their professional development. Risks like privacy, resolving the issues of the complexity of usage and implementation are essential. Training programs for transformation of conventional teaching into social media tools embedded classroom practices should be provided particularly for the older faculty members.

\section{ACKNOWLEDGMENT}

The author would like to thank A. K. Mohammed for contributing to this research merely in the collection and coding of the data.

\section{REFERENCES}

[1] A. Ratliff, "Are they listening? Social media on campuses of higher education," The Journal of Technology in Student Affairs, vol. 38, pp. 65-69, 2011.

[2] C. Piotrowski, "Emerging research on social media use in education: A study of dissertations," Research in Higher Education Journal, vol. 27, pp. 1-12, 2015a.

[3] C. H. F. Davis III, R. Deil-Amen, C. Rios-Aguilar, and M. S. González Canché, "Social media, higher education, and community colleges: a research synthesis and implications for the study of two-year institutions," Community College Journal of Research and Practice, vol. 39, no. 5, pp. 409-422, 2014.

[4] M. Thomas and H. Thomas, "Using new social media and web 2.0 technologies in business school teaching and learning," Journal of Management Development, vol. 31 no. 4, pp. 358-367, 2012.

[5] T. Anderson,"Challenges and opportunities for use of social media in higher education, " Journal of Learning for Development - JL4D, vol. 6, no.1, pp. 1-9, 2019.

[6] B.A. Legaree, "Considering the changing face of social media in higher education," FEMS microbiology letters, vol. 362, no.16, pp. 1-3, 2015.

[7] S. Manca and M. Ranieri, "Implications of social network sites for teaching and learning. where we are and where we want to go," Education and Information Technologies, vol. 22, no. 2, pp.605-622, 2015.

[8] S. Manca and M. Ranieri, "Facebook and the others. potentials and obstacles of social media for teaching in higher education," Computers \& Education, vol. 95, pp. 216-230, Apr. 2016.

[9] J. Seaman, and H. Tinti-Kane, Social media for teaching and learning, UK: Pearson Learning Systems, 2013.

[10] J. E. Rodriguez, "Social media use in higher education: key areas to consider for educators," Journal of Online Learning and Teaching, vol. 7, no. 4, pp.539-550, 2011.

[11] N. Selwyn, "Social media in higher education," The Europa world of learning, vol. 1, pp.1-10, 2012.

[12] A.Y. Abdelraheem and A.M. Ahmed, "Electronic social media in teaching: usages, benefits, and barriers as viewed by sudanese faculty members," American International Journal of Social Science, vol. 4, no. 5, pp.58-68, 2015.

[13] H. Ajjan, and R. Hartshorne, "Investigating faculty to adopt web 2.0 technologies," Theory. Internet and Higher Education, vol. 11, pp. 7180, 2008.

[14] S. D. Frazier, "An analysis of the current use and intentions to use mobile learning strategies among full-time community college faculty," (Unpublished Doctoral dissertation). University of South Carolina, 2013.

[15] A. J. Lenartz, "All my rowdy "friends": the use of social media in higher education," ProQuest LLC. (Ed. Doctoral dissertation) Northern Arizona University, 2012.

[16] E. A. Mansour, "The use of social networking sites (snss) by the faculty members of the school of library \& information science," The Electronic Library, vol. 33, no. 3, pp. 524-546, 2015.

[17] G. Veletsianos, and R. Kimmons, "Scholars and faculty members' lived experiences in online social networks," The Internet and Higher Education, vol. 16, pp.43-50, 2013.

[18] C. Piotrowski, "Scholarly research on educational adaptation of social media: is there evidence of publication bias?, " College Student Journal, vol. 49, no. 3, pp. 447-451, 2015 b.

[19] M. D. Robyler, M. McDaniel, M. Webb, J. Herman, and J. Witty, "Findings on facebook in higher education: a comparison of college faculty and student uses and perceptions of social networking sites," The Internet and higher education, vol. 13, no. 3, pp. 134-140, 2010.

[20] S. K. Sahu, "The impact of social media on university learning," Journal of Library and Information Sciences vol. 2, no.1, pp. 83-97, 2014. 
[21] A. E. Sobaih, M. A. Moustafa, P. Ghandforoush, and M. Khan, "To use or not to use? social media in higher education in developing countries," Computers in Human Behavior, vol. 58, pp. 296-305, 2016.

[22] S. Manca, and M. Ranieri, "Yes for sharing, no for teaching!": social media in academic practices," The Internet and Higher Education, vol. 29, pp.63-74, 2016.

[23] P. A. Tess "The role of social media," Computers in Human Behavior, vol. 29, pp. 60-68, 2013.

[24] T. Tuten, and M. Marks, "The adoption of social media as educational technology among marketing educators," Marketing Education Review, vol. 22, no. 3, pp. 201-214, 2012.

[25] N. Kosarassawadee, A. Sukweses, and C. Tantarangsee, "The role of social media for instructional purposes," International Journal of Languages, Literature and Linguistics, vol. 4, no. 1, pp. 11-17, Mar. 2018.

[26] D. Roebuck, S. Siha, and R.L. Bell, "Faculty usage of social media and mobile devices: analysis of advantages and concerns," Interdisciplinary Journal of E-Learning and Learning Objects, vol. 9, pp.171-192, 2013.

[27] A. J. Y. Zaidieh, "The use of social networking in education: challenges and opportunities", World of Computer Science and Information Technology Journal (WCSIT), vol. 2, no.1, pp. 18-21, 2012.

[28] M. Thomas, and T. Howard, "Using new social media and web 2.0 technologies in business school teaching and learning," Journal of Management Education, vol. 31, no.4, pp. 358-367, 2012.

[29] E. Mutekwe, "Higher education and the social media technology: a dilemma unfolding in institutions of higher learning," Journal of Education and Human Development, vol. 4,no. 3, pp. 119-33, 2015.

[30] A. Gruzd, K. Staves, and, A. Wilk, "Connected scholars: examining the role of social media in research practices," Computers in Human Behavior, vol. 28, pp. 2340-2350, 2012.

[31] M. Au, J. Lam, and R. Chan, "social media education: barriers and critical issues. technology in education. transforming educational practices with technology," pp.199-205, 2015.

[32] M. O. Kaiser, "Kaiser-Meyer-Olkin measure for identity correlation matrix," Journal of the Royal Statistical Society, vol. 52, pp.296-298, 1974.

[33] D. George, and M. Mallery, "Using spss for windows step by step: a simple guide and reference", Boston, MA: Allyn \& Bacon, 2003.

[34] E. K. Kelloway, Using lisrel for structural equation modeling: a researcher's guide. Thousand Oaks, CA: Sage, 1998.

[35] E. Collins, and B. Hide, "Use and relevance of web 2.0 resources for researchers", In Publishing in the Networked World: Transforming the Nature of Communication 14th International Conference on Electronic Publishing, pp. 271-289, 2010.

[36] M. Moran, J. Seaman, and H. Tinti-Kane, Blogs, wikis, podcasts and Facebook: how today's higher education faculty use social media. Boston, MA: Pearson Learning Solutions, 2012.

[37] R. G. Henderson, and B.F. Chapman, "Business educators' perceptions concerning mobile learning (m-learning)," Delta Pi Epsilon Journal, vol. 54, no. 1, pp. 16-26, 2012.

[38] M. D. Gonzalez, B. P. Davis, D. Lopez, C. Munoz, and G. Soto , "Integration of social media in higher education environments," Insights to a Changing World Journal, vol. 3, pp. 43-62, 2013.

[39] J.A. Delello, R.R. McWhorter, and K.M. Camp, "Using social media as a tool for learning: A multi-disciplinary study," International Journal on E-Learning, vol. 14, no.2 , pp.163-180, 2015.

[40] M.V. Vivakaran, and M. Neelamalar, "Utilization of social media platforms for educational purposes among the faculty of higher education with special reference to tamil nadu," Higher Education for the Future, vol. 5, no. 1, pp. 4-19, 2018.
[41] S. Bașaran, S. Rukundo, "University students' and faculty's views on ethical use of facebook within ict context," INTED2018 Proceedings. pp. 3679-3688. DOI:10.21125/inted.2018.0706, 2018.

[42] S. Başaran, G. O. Hama, "Exploring faculty members' views on adoption of cloud computing in education," International Scientific Conference "Society, Integration, Education - SIE2018". DOI: 10.17770/sie2018vol1.3290, 2018.

[43] S. Başaran, "Investigating university students' views on flipped classroom approach," INTED2019 Proceedings. pp. 8050-8059. DOI: 10.21125/inted.2019.1998, 2019.

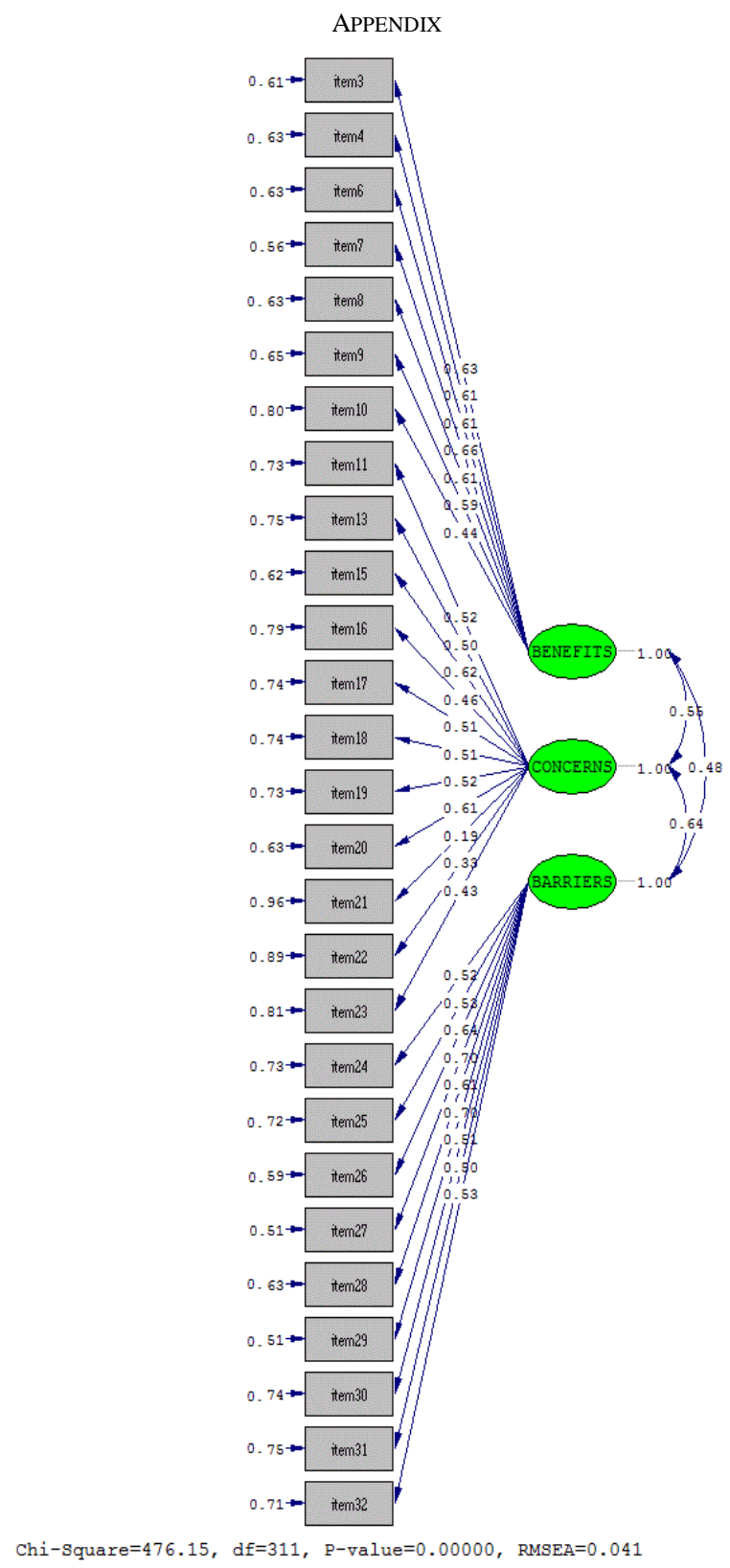

Fig. 2. Confirmatory Factor Analysis LISREL Output. 
TABLE. II. MEAN, Standard DEVIATION, Rotation Sum OF SQUAREd LoAdingS AND Reliability (N=324)

\begin{tabular}{|l|l|l|l|l|l|l|l|}
\hline FACTOR & No. of Items & M & SD & Total & \%ofVariance & Cumulative\% & Cronbach $\boldsymbol{\alpha}$ \\
\hline BRR & 9 & 3.69 & 0.65 & 4.550 & 14.218 & 14.218 & 0.84 \\
\hline BNF & 10 & 3.74 & 0.62 & 3.917 & 12.240 & 26.458 & 0.82 \\
\hline CRN & 13 & 3.72 & 0.50 & 3.701 & 11.564 & 38.022 & 0.79 \\
\hline TOTAL & 32 & - & - & - & - & - & 0.89 \\
\hline
\end{tabular}

TABLE. III. ROTATED FACTOR MATRIX, MEANS AND STANDARD DEVIATIONS

\begin{tabular}{|c|c|c|c|c|c|}
\hline FACTORS & 1 & 2 & 3 & $\mathbf{M}$ & SD \\
\hline BARRIERS & & & & 3.69 & .65 \\
\hline Q29 - Grading and assessment & .73 & & & 3.61 & .99 \\
\hline Q26- Takes too much time to learn or use & .69 & & & 3.58 & 1.06 \\
\hline Q27 - Lack of integration with LMS & .67 & & & 3.56 & 1.04 \\
\hline Q28 - Inability to measure effectiveness & .67 & & & 3.61 & .97 \\
\hline Q31- Concerns about privacy & .62 & & & 3.73 & .94 \\
\hline Q32 - Integrity of student submissions & .60 & & & 4.01 & .98 \\
\hline Q25 - Lack of support at my institution & .60 & & & 3.63 & .97 \\
\hline Q30 - Separate course and personal accounts & .59 & & & 3.73 & .96 \\
\hline Q24 - Lack of knowledge of the use of social media in education & .49 & & & 3.72 & .96 \\
\hline BENEFITS & & & & 3.74 & .62 \\
\hline Q9 - Using social media improves students' creativity and output. & & .73 & & 3.67 & 1.03 \\
\hline Q8 - Using social media allows my students to receive informative and rewarding feedback from multiple sources. & & .73 & & 3.71 & .99 \\
\hline Q4 - I do believe that the information-sharing feature of social media greatly enhanced my learning experiences. & & .68 & & 3.78 & 1.01 \\
\hline Q3 - I believe social media used as a supplementary learning tool holds promise for enhancing sense of classroom community. & & .67 & & 3.79 & 1.12 \\
\hline Q10 - I believe using social media allows more interaction between students from different countries. & & .65 & & 3.68 & .98 \\
\hline $\begin{array}{l}\text { Q7 - Exposing students to the latest technology helps prepare them for work and provides an opportunity for them to acquire } \\
\text { additional skills. }\end{array}$ & & .60 & & 3.77 & .98 \\
\hline $\begin{array}{l}\text { Q6 - I believe the interactive nature of social media allows students to participate in collaborative work and create work where } \\
\text { the Quality of the whole may well exceed the sum of its parts. }\end{array}$ & & .49 & & 3.73 & .97 \\
\hline $\begin{array}{l}\text { Q5 - I think students are more engaged with Social Media learning than other e-learning platforms used. because students have } \\
\text { more interactional opportunities for sharing personal interests and exchanging learning resources in addition to discussing } \\
\text { course. }\end{array}$ & & .36 & & 3.68 & 1.01 \\
\hline Q2 - Social media allows me to find and share educational resources. & & .38 & & 3.78 & .88 \\
\hline $\begin{array}{l}\text { Q1 - Social media allows me to discuss topics of interest and/ or to communicate with my fellow students about course-related } \\
\text { topics }\end{array}$ & & .32 & & 3.84 & .99 \\
\hline CONCERNS & & & & 3.72 & .50 \\
\hline Q12 - Using social media to supplement face-to-face courses can become too time intensive. & & & .34 & 3.90 & .86 \\
\hline Q17 - I believe there should be an institutional approach to how and what social media is used for learning. & & & .62 & 3.66 & .99 \\
\hline $\begin{array}{l}\text { Q16 - I am concerned over who would be responsible if students or professors say something online that results in lawsuit } \\
\text { against. }\end{array}$ & & & .60 & 3.84 & .82 \\
\hline Q14 - I sometimes feel overwhelmed by overabundance of information shared. & & & .59 & 3.53 & .96 \\
\hline Q15 - I have concerns about vague copyright and intellectual property issues involved in social media. & & & .58 & 3.67 & 1.04 \\
\hline Q18 - I am concerned who is monitoring the social media for inappropriate or offensive use and how we deal with it. & & & .55 & 3.71 & .82 \\
\hline Q20 - Risks to the personal privacy of students. & & & .51 & 3.42 & .93 \\
\hline $\begin{array}{l}\text { Q13 - I believe using a private social networking appears to be the answer to struggle with issues of privacy and information } \\
\text { security. }\end{array}$ & & & .46 & 3.65 & 1.11 \\
\hline Q19 - Risks to the personal privacy of faculty. & & & .45 & 3.54 & 1.02 \\
\hline Q11- I feel concerned about the threat of spam and phishing attacks when using social media in the classroom. & & & .43 & 3.70 & .97 \\
\hline Q22 - Others outside of class should not be able to view class discussions. & & & .39 & 3.94 & .86 \\
\hline Q21 - Others outside of class should not be able to view class-related content. & & & .34 & 3.96 & .84 \\
\hline Q23 - Others outside of class should not be able to participate in class discussions. & & & .33 & 3.82 & .96 \\
\hline
\end{tabular}

